\title{
Low Education as a Risk Factor for Undiagnosed Angina
}

\author{
Michael M. McKee, MD, MPH, Paul C. Winters, MS, and Kevin Fiscella, MD, MPH
}

Background: Early awareness, recognition, and treatment of angina can help prevent or delay an acute myocardial infarction and potentially delay death. A patient's educational level may affect a physician's diagnosis of angina and/or a patient's symptom recognition. The objective of this study was to determine whether low education is a risk factor for undiagnosed angina.

Methods: This was a cross-sectional observational study based on data from the National Health and Nutrition Examination Survey 2001 to 2008, providing a nationally representative sample of adults $\geq 40$ years of age with angina based on physician diagnosis, presence of angina symptoms based on the Rose Questionnaire, or both. Educational attainment (high school or less vs more than high school) was the independent variable of interest. Undiagnosed angina (angina symptoms in the absence of angina diagnosis) was the dependent variable. We used logistic regression to control for age, sex, race/ethnicity, income, and health care visit during the past year.

Results: Low education was associated with undiagnosed angina (odds ratio: 1.43; 95\% confidence interval: 1.01-2.03). Other undiagnosed angina predictors included being female, being black, and having no health care visit during the past year.

Conclusions: Low education is associated with undiagnosed angina. These results underscore the need for providers to ask about angina symptoms and confirm patients' understanding of their angina diagnosis among those with low education. (J Am Board Fam Med 2012;25:416-421.)

Keywords: Angina Pectoris; Cross-Sectional Studies; Education; Health Knowledge, Attitudes, Practice

More than 6 million Americans are affected by angina pectoris and it is the primary symptom in roughly half of patients with coronary artery disease. ${ }^{1}$ According to 2008 national data, $4.1 \%$ of adults reported that they were informed of an an-

This article was externally peer reviewed.

Submitted 30 September 2011; revised 28 December 2011; accepted 12 January 2012.

From the Family Medicine Research Programs, Department of Family Medicine, University of Rochester School of Medicine and Dentistry, Rochester, NY.

Funding: The research was supported by the National Heart Lung and Blood Institute (1R01 HL081066-01A2). Dr. McKee is currently supported by grant K01 HL103140-01 from the National Heart, Lung, and Blood Institute (NHLBI) of the National Institutes of Health (NIH).

Conflict of interest: none declared.

Disclaimer: The contents of this article are solely the responsibility of the authors and do not necessarily represent the official views of the National Heart, Lung and Blood Institute.

Corresponding author: Michael M. McKee, MD, MPH, Assistant Professor, Department of Family Medicine, Family Medicine Research Programs, 1381 South Avenue, Rochester, NY 14620 (E-mail: michael_mckee@ urmc.rochester.edu). gina or CAD diagnosis. ${ }^{2}$ Early recognition and treatment of angina can help prevent or delay the onset of an acute myocardial infarction and potentially death, yet many lifesaving treatments such as thrombolytic therapy, aspirin, and nitroglycerin are not used (or their use is delayed) because of patients' failure to recognize cardiac symptoms. ${ }^{3}$

Low educational attainment is associated with low health literacy and with less effective health communication, which affects patients' abilities to convey pertinent health information to their providers. Low education also is associated with lower awareness and comprehension of physician diagnoses and recommendations. ${ }^{4}$ Adults who completed high school or less display lower literacy, ${ }^{5}$ lower health literacy, ${ }^{6,7}$ and lower cardiac health literacy (ie, cardiac symptom recognition). ${ }^{8}$ In a 2005 national sample, low education was associated with lower recognition of 5 heart attack symptoms. ${ }^{\text {? }}$ There is a growing body of evidence linking low education to worse cardiovascular outcomes. . $^{210-12}$ Given the association between low education and 
low cardiac health literacy, we hypothesized that individuals with low education would more often report angina symptoms that were undiagnosed than would those with higher education.

\section{Methods \\ Sample}

We used 2001 to 2008 data from the National Health and Nutrition Examination Survey (NHANES), a nationally representative, stratified, multistage probability sample of the civilian noninstitutionalized population of the United States. Since 1999, NHANES has been conducted on a continuous basis, with data released in 2-year cycles. Data collection methods include an interviewer-administered questionnaire using computer-assisted personal interview technology and physical examinations performed in mobile examination centers. In addition, NHANES oversampled African Americans, Hispanics, and persons aged 60 years and older. ${ }^{13}$ Our study sample included 1028 adults (497 men and 531 women) aged 40 years and older with either diagnosed or undiagnosed angina (details provided later) with complete data on age, race, sex, income, and health care variables.

\section{Measures}

Angina

We assessed angina in 2 ways. The first was based on an affirmative response to the question, "Has a doctor or other health professional ever told you that you had angina, also called angina pectoris?" The second was based on the presence of angina symptoms using the Rose Questionnaire, ${ }^{14}$ a standardized and validated assessment tool designed to differentiate cardiac from noncardiac chest pain. It has been used widely in a variety of cardiovascular epidemiologic studies over the past several decades $^{10,15}$ within multiple countries and among persons of different races, sexes, languages, educational levels, and occupations. ${ }^{10,16-19}$ It has fair sensitivity and specificity for angina compared with various clinical assessments: clinical judgment (sensitivity of $81 \%$ and specificity of $97 \%),{ }^{16}$ thallium scintigraphy (sensitivity of $40 \%$ to $50 \%$ and specificity of $56 \%$ to $77 \%)$, ${ }^{20,21}$ coronary angiography (sensitivity of $50 \%$ and specificity of $75 \%$ ), ${ }^{22}$ and exercise electrocardiography (sensitivity of 57\% and specificity of $47 \%$ ). ${ }^{22}$ The 9 questions on the Rose Questionnaire are shown in Table 1.
Table 1. Questions on the Rose Questionnaire

\begin{tabular}{|c|c|}
\hline 1. & $\begin{array}{l}\text { Have you ever had any pain or discomfort in your } \\
\text { chest? }\end{array}$ \\
\hline 2. & Do you get it when you walk uphill or hurry? \\
\hline 3. & $\begin{array}{l}\text { Do you get it when you walk at an ordinary pace on } \\
\text { level ground? }\end{array}$ \\
\hline 4. & What do you do if you get it while you are walking? \\
\hline 5 . & $\begin{array}{l}\text { Do you stop or slow down or continue at the same } \\
\text { pace? }\end{array}$ \\
\hline 6. & If you stand still, what happens to it? \\
\hline 7. & Is the pain or discomfort relieved or not relieved? \\
\hline 8. & How soon is the pain relieved? \\
\hline 9. & Where is the pain or discomfort located? \\
\hline
\end{tabular}

We used NHANES criteria to identify those with angina based on responses to this questionnaire: chest pain or discomfort (yes to question 1) that fulfilled all the following criteria: (1) was brought on by exertion (yes to either question 2, 3 , or both); (2) forced the subject to slow down or stop (question 4); (3) was relieved if the subject did so (yes to question 5), (4) was relieved within 10 minutes (question 6), (5) was located in the central or left anterior chest (question 9).

Undiagnosed angina. We defined undiagnosed angina as a dependent variable based on the presence of angina symptoms in the absence of a physician diagnosis.

Low education. Self-reported educational attainment was our main independent variable. We operationalized it as high school education or less (low education) and more than high school education (referent).

\section{Covariates}

We included self-reported demographic covariates: age (40-54 years, 55-64 years, $\geq 65$ years); sex (male, female); race/ethnicity (Mexican American/ other Hispanic, non-Hispanic white, non-Hispanic black, other); and family poverty income ratio (federal poverty income thresholds that account for household size). We assessed health care access based on the participant's report of whether they had seen a doctor/health professional during the past year (yes/no).

\section{Statistical Analysis}

NHANES uses a complex sampling design involving stratification, clustering, and oversampling of certain groups that results in unequal probability of selection. The statistical analyses incorporated stra- 
tum, primary sampling units, and appropriate interview sampling weights to produce unbiased estimates of the noninstitutionalized US population. ${ }^{23}$ We used a subpopulation statement in SUDAAN software (RTI International, Research Triangle Park, NC) to generate estimates for the US population aged 40 years and older. Bivariate associations were determined using $\chi^{2}$ tests. We assessed the independent association between low education and undiagnosed angina using logistic regression that controlled for demographics (sex, age, race/ ethnicity, income, and education) and a health carerelated variable (health care during past year). All statistical analyses were conducted using SAS-callable SUDAAN version 10.0.1 and SAS version 9.2 (SAS Institute, Inc, Cary, NC).

\section{Results}

The final sample included 1028 adults, of whom 359 had angina symptoms but reported no previous diagnosis of angina reported by their physicians.
Persons with undiagnosed angina were younger and more often women, black, and less likely to have seen a physician/health care professional during the past year compared with those without undiagnosed angina (Table 2). In an adjusted analysis, low education was significantly associated (odds ratio [OR], 1.43; 95\% confidence interval [CI], 1.01-2.03) with undiagnosed angina (Table 3). Other significant predictors of undiagnosed angina included being female (OR, 1.95; 95\% CI, 1.362.81), black (OR, 2.56; 95\% CI, 1.67-3.93), and not having seen a physician/health care professional during the past year (OR, 2.81; 95\% CI, 1.535.16). There were no significant interactions between education and other variables in the model.

We examined the extent to which having had a health care visit during the past year affected our findings. When we excluded this variable from our model, there was little change in the risk associated with low education (OR, 1.44; 95\% CI, 1.02-2.03).

Table 2. Characteristics of Participants with Undiagnosed and Diagnosed Angina

\begin{tabular}{|c|c|c|c|}
\hline \multirow[b]{2}{*}{ Variable } & \multicolumn{2}{|c|}{ Undiagnosed Angina Symptoms } & \multirow[b]{2}{*}{$P^{*}$} \\
\hline & Yes & No & \\
\hline All & $62.8(359)$ & $37.2(669)$ & \\
\hline Education & & & .1164 \\
\hline High school/equivalent or less & $59.0(237)$ & $53.5(390)$ & \\
\hline More than high school & $41.0(122)$ & 46.5 (279) & \\
\hline Sex & & & .0004 \\
\hline Female & $62.6(219)$ & $47.8(312)$ & \\
\hline Male & $37.4(140)$ & $52.2(357)$ & \\
\hline Age, years & & & $<.0001$ \\
\hline $40-<55$ & $50.4(141)$ & $22.3(103)$ & \\
\hline $55-<65$ & $23.4(92)$ & $21.5(127)$ & \\
\hline$\geq 65$ & $26.2(126)$ & $56.2(439)$ & \\
\hline Race/ethnicity & & & $<.0001$ \\
\hline Hispanic/Mexican & $7.5(62)$ & $6.4(108)$ & \\
\hline Non-Hispanic black & $17.7(104)$ & $6.3(76)$ & \\
\hline Non-Hispanic white & $68.7(182)$ & $82.7(460)$ & \\
\hline Other & $6.0(11)$ & $4.7(25)$ & \\
\hline Poverty income ratio (\%) & & & .0134 \\
\hline$<100$ & $23.4(100)$ & $13.8(109)$ & \\
\hline $100-<200$ & $26.3(113)$ & $31.8(262)$ & \\
\hline $200-<300$ & $14.9(60)$ & $17.4(109)$ & \\
\hline$\geq 300$ & $35.3(86)$ & $37.0(189)$ & \\
\hline Health care during the past year & & & .0020 \\
\hline No & $10.0(28)$ & $3.4(22)$ & \\
\hline Yes & $90.0(331)$ & $96.6(647)$ & \\
\hline
\end{tabular}

Values provided as \% (n). Column percentages reported are weighted to the noninstitutionalized US population.

${ }^{*} \chi^{2}$ test for association. 
Table 3. Predictors of Undiagnosed Angina

\begin{tabular}{|c|c|c|}
\hline Variable & Odds Ratio (95\% Limits) & $P^{*}$ \\
\hline Education & & .0446 \\
\hline $\begin{array}{l}\text { High school/equivalent } \\
\text { or less }\end{array}$ & $1.43(1.01-2.03)$ & \\
\hline More than high school & $1.00(1.00-1.00)$ & \\
\hline Sex & & .0005 \\
\hline Female & $1.95(1.36-2.81)$ & \\
\hline Male & $1.00(1.00-1.00)$ & \\
\hline Age, years & & $<.0001$ \\
\hline $40-<55$ & $1.00(1.00-1.00)$ & \\
\hline $55-<65$ & $0.51(0.33-0.79)$ & \\
\hline$\geq 65$ & $0.23(0.17-0.31)$ & \\
\hline Race/ethnicity & & .0003 \\
\hline Hispanic/Mexican & $0.83(0.49-1.39)$ & \\
\hline Non-Hispanic black & $2.56(1.67-3.93)$ & \\
\hline Non-Hispanic white & $1.00(1.00-1.00)$ & \\
\hline Other & $1.40(0.60-3.25)$ & \\
\hline Poverty income ratio (\%) & & .7654 \\
\hline$<100$ & $1.08(0.64-1.81)$ & \\
\hline $100-<200$ & $0.86(0.54-1.37)$ & \\
\hline $200-<300$ & $0.89(0.45-1.73)$ & \\
\hline$\geq 300$ & $1.00(1.00-1.00)$ & \\
\hline $\begin{array}{l}\text { Health care visit during } \\
\text { the past year }\end{array}$ & & .0012 \\
\hline No & $2.81(1.53-5.16)$ & \\
\hline Yes & $1.00(1.00-1.00)$ & \\
\hline
\end{tabular}

Logistic regression model with all variables in the model. ${ }^{*}$ Wald test.

\section{Discussion}

In national survey of adults 40 years of age and older, we found that low education was associated with a $43 \%$ greater likelihood of undiagnosed angina. These effects persisted after controlling for age, sex, race, income, and having a physician visit during the past year. These findings are consistent with previous studies suggesting that low education may pose awareness and health communication issues, resulting in possible diagnosis errors and treatment delays. ${ }^{24,25}$ To our knowledge, these findings, based on national data using a validated measure for angina symptoms, are novel.

Our data do not indicate why low education is associated with undiagnosed angina symptoms. Our analysis controlled for having had a visit with health care provider within the past year, so having a recent physician visit is unlikely to be the sole explanation. Potentially, this association reflects low patient health literacy and resulting breakdowns in patient-provider communication. There is a strong association between low education and low health literacy. ${ }^{6,7,26}$ Patients with low education are less likely to associate angina symptoms with heart disease. ${ }^{8,9}$ Clinicians may not appreciate that patients with low education are describing angina or may not clearly communicate their diagnosis to the patients. Physicians often use medical jargon that is poorly understood, particularly by patients with low health literacy. ${ }^{27,28}$ Other communication barriers include limited patient knowledge, patient embarrassment when asking questions, and suboptimal physician communication behavior. ${ }^{29}$ When caring for patients with low education, physicians tend to listen less, provide less reassurance, underestimate the information patients desire, fail to engage the patient in shared decision making, offer patients too little health information, and display less empathy. ${ }^{30,31}$ For these reasons, we suspect that our results may reflect communication failures between physicians and their patients with low education.

Other patient demographic characteristics besides low education are also significantly associated with undiagnosed angina. These include being female, black, and not having seen a physician/health care professional during the past year. Although these reflect post hoc findings warranting replication through further study, they suggest that clinicians be especially attuned to unrecognized angina among these groups.

Less than $20 \%$ of women older than age 35 are aware that cardiovascular disease is a major cause of death among women. ${ }^{32}$ The Atherosclerosis Risk in Communities study, which used the Rose Questionnaire, revealed higher rates of angina among women compared with men. ${ }^{33}$ Undiagnosed angina may be attributable to the language used during physician-patient encounters and inaccurate physician beliefs. Women ask more questions than men and try to retrieve more medical information but are less likely to be diagnosed as suffering from cardiovascular disease and are more likely to have their symptoms attributed to emotional or psychosomatic causes. ${ }^{34}$

Despite higher burdens in cardiovascular diseases, blacks lag behind whites in cardiovascular disease recognition and awareness. ${ }^{2,33}$ Cardiovascular disparities among blacks are largely attributable to lower educational attainments and more risk factors, particularly hypertension. ${ }^{11}$

Individuals older than 55 years of age were less likely to have undiagnosed angina compared with 
individuals aged 40 to 54 years. This may be explained by several factors. Increasing age is associated with greater risk for cardiovascular disease, including angina. ${ }^{2}$ The association of older age with greater likelihood of diagnosis may increase cardiovascular awareness among individuals in this age group. In addition, physicians also may have higher suspicion for angina and cardiovascular diseases for people in this age group.

Low education is associated with higher risk of developing angina and worse treatment and survival rates for both fatal and nonfatal cardiac events. ${ }^{1}$ Thus, it is critical for physicians to be cognizant of the communication needs of persons with low education and to employ principles of clear communication, including teach-back. ${ }^{35,36}$ Specifically, providers and staff can communicate more effectively with less educated patients using the following steps: providing patients with adequate time and opportunity to voice their concerns and describe their symptoms; showing respect, including listening attentively; encouraging the patient to ask follow-up questions; rephrasing complex questions or terms into plain language; using appropriate pictures and graphics to enhance patients' comprehension of the material being discussed; encouraging the patient to explain their understanding in their own words ${ }^{37}$; and actively engaging the patient in decision making.

Health information provided by physicians can be reinforced through public health programs and community outreaches that target persons with low education using simple and informative health messages about cardiac symptoms. Information also should include steps to take if cardiac symptoms occur, including contacting emergency medical services immediately. ${ }^{38}$

Our findings are subject to several limitations. Data are self-reported and potentially subject to recall and reporting bias. No cause and effect can be established because of the nature of the crosssectional design. We cannot pinpoint where breakdowns in communication occurred. Further study is needed to determine whether higher prevalence of unrecognized angina among those with low education results from patients failing to report symptoms or from clinicians failing to ask about symptoms, recognize symptoms, or both.

Most participants likely completed their formal education more than 20 years ago. However, the effect of educational attainment on literacy persists over time. National data show a similar pattern between years of education and reading ability regardless of age. ${ }^{39}$ Finally, we cannot exclude the possibility that other factors not accounted for in our model may confound our results.

\section{Conclusions}

Our findings show that among a national sample of adults with presumed angina, low education is associated with undiagnosed angina. Potentially, this may contribute to worse cardiovascular outcomes for this group. Additional research is needed to determine the reasons why low education is associated with undiagnosed angina and which interventions are mostly likely to improve diagnosis. Physicians should ask about the presence of angina symptoms, particularly among adults with low education, including women, blacks, and those who have not received health care during the past year.

\section{References}

1. Mozaffarian D, Byrson CL, Spertus JA, McDonell MB, Fihn SD. Anginal symptoms consistently predict total mortality among outpatients with coronary artery disease. Am Heart J 2003;146(6): $1015-22$.

2. Lloyd-Jones D, Adams RJ, Brown TM, et al. Heart disease and stroke statistics-2010 update: a report from the American Heart Association. Circulation 2010;121:e46-215.

3. Dracup K, Moser DK, Eisenberg M, Meischke H, Alonzo AA, Braslow A. Causes of delay in seeking treatment for heart attack symptoms. Soc Sci Med 1995;40:379-92.

4. Smith SK, Dixon A, Trevena L, Nutbeam D, McCaffery KJ. Exploring patient involvement in healthcare decision making across different education and functional health literacy groups. Soc Sci Med 2009; 69(12):1805-12.

5. Kirsch IS, Jungeblut A, Jenkins L, Kolstad A. Adult literacy in America: a first look at the findings of the National Adult Literacy Survey. Washington, DC: Department of Education; 2002.

6. Berkman ND, DeWalt DA, Pignone MP, et al. Literacy and health outcomes. Rockville, MD: Agency for Health Care Research and Quality; 2004.

7. Kutner M, Greenberg E, Jin Y, Paulsen C. The health literacy of America's adults: results from the 2003 National Assessment of Adult Literacy. Washington, DC: National Center for Education Statistics; 2006.

8. Safeer RS, Cooke CE, Keenan J. The impact of health literacy on cardiovascular disease. Vasc Health Risk Manag 2006;2:457-64. 
9. Centers for Disease Control and Prevention (CDC). Disparities in adult awareness of heart attack warning signs and symptoms: 14 states, 2005. MMWR Morb Mortal Wkly Rep 2008;57:175-9.

10. Reeder B, Lui L, Horlick L. Sociodemographic variation in the prevalence of cardiovascular disease. Can J Cardiol 1996;12:271-7.

11. Hozawa A, Folsom A, Sharrett A, Chambless L. Absolute and attributable risks of cardiovascular disease incidence in relation to optimal and borderline risk factors: comparison of African American with white subjects: Atherosclerosis Risk in Communities Study. Arch Intern Med 2007;167:573-9.

12. Centers for Disease Control and Prevention (CDC). Receipt of outpatient cardiac rehabilitation among heart attack survivors-United States, 2005. MMWR Morb Mortal Wkly Rep 2008;57:89-94.

13. Centers for Disease Control and Prevention (CDC). Analytic and reporting guidelines: the National Health and Nutrition Examination Survey (NHANES). Hyattsville, MD: National Center for Health Statistics Centers for Disease Control and Prevention; 2006.

14. Rose GA. Ischemic heart disease. Chest pain questionnaire. Milbank Mem Fund Q 1965;43:32-9.

15. Rose G. The diagnosis of ischaemic heart pain and intermittent claudication in field surveys. Bull World Health Organ 1962;27:645-58.

16. Heyden S, Bartel A, Tabesh E, et al. Angina pectoris and the Rose Questionnaire. Arch Intern Med 1971; 128:961-4.

17. Graff-Iversen S, Selmer R, Løchen M. Rose angina predicts 23-year coronary heart disease mortality in women and men aged 40-49 years. Heart 2007;94:482-6.

18. Lacrolx A, Haynes S, Savage D, Havlik R. Rose Questionnaire angina among United States black, white, and Mexican-American women and men. Prevalence and correlates from The Second National and Hispanic Health and Nutrition Examination Surveys. Am J Epidemiol 1989;129:669-86.

19. Prabhakaran D, Shah P, Chaturvedi V, Ramakrishnan L, Manhapra A, Reddy K. Cardiovascular risk factor prevalence among men in a large industry of northern India. Natl Med J India 2005;18:59-65.

20. Bass E, Follansbee WP, Orchard TJ. Comparison of a supplemented Rose questionnaire to exercise-thallium testing in men and women. J Clin Epidemiol 1989;42:385-94.

21. Garber C, Carleton RA, Heller GV. Comparison of "Rose questionnaire angina" to exercise-thallium scintigraphy; different findings in males and females. J Clin Epidemiol 1992;45:15-20.

22. Midwall J, Ambrose J, Pichard A, Abedin Z, Hermanj MV. Angina pectoris before and after myocardial infarction: angiographic correlations. Chest 1982;81:681.

23. National Center for Health Statistics. The National Health and Nutrition Examination Survey (NHANES) analytic and reporting guidelines. 2006. Available from: http://www.cdc.gov/nchs/data/nhanes/nhanes_03_04/ nhanes_analytic_guidelines_dec_2005.pdf. Accessed August 15, 2011.

24. Gazmararian JA, Williams MV, Peel J, Baker DW. Health literacy and knowledge of chronic disease. Patient Educ Couns 2003;51:267-75.

25. DeWalt DA, Boone RS, Pignone MP. Literacy and its relationship with self-efficacy, trust, and participation in medical decision making. Am J Health Behav 2007;31(Suppl 1):S27-35.

26. Gazmararian JA, Curran JW, Parker RM, Bernhardt JM, DeBuono BA. Public health literacy in America: an ethical imperative. Am J Prev Med 2005;28:317-22.

27. Lerner E, Jehle D, Janicke D, Moscati R. Medical communication: do our patients understand? Am J Emerg Med 2000;18:764-6.

28. Spiro D, Heidrich F. Lay understanding of medical terminology. J Fam Pract 1983;17:277-9.

29. Nielsen-Bohlman L, Panzer A, Kindig D, eds. Health literacy: a prescription to end confusion. Washington, DC: The National Academies Press; 2004.

30. Willems S, De Maesschalck S, Deveugele M, Derese A, De Maeseneer J. Socio-economic status of the patient and doctor-patient communication: does it make a difference? Patient Educ Couns 2005;56:139-46.

31. Fiscella K, Goodwin M, Stange K. Does patient educational level affect office visits to family physicians? J Natl Med Assoc 2002;94:157-65.

32. Biswas MS, Calhous PS, Bosworth HB, Bastian LA. Are women worrying about heart disease? Womens Health Issues 2002;12:204-11.

33. National Heart, Lung, and Blood Institute. Incidence and prevalence: 2006 chart book on cardiovascular and lung diseases. Bethesda, MD: National Institute of Health; 2006.

34. Philpott S, Boynton PM, Feder G, Hemingway H. Gender differences in descriptions of angina symptoms and health problems immediately prior to angiography: the ACRE study. Appropriateness of Coronary Revascularisation study. Soc Sci Med 2001;52:1565-75.

35. National Quality Forum. Safe practices for better healthcare. Washington, DC: National Quality Forum; 2003.

36. Kripalani S, Weiss B. Teaching about health literacy and clear communication. J Gen Intern Med 2006; 21:888-90.

37. Schillinger D, Piette J, Grumbach K, et al. Physician communication with diabetic patients who have low health literacy. Arch Intern Med 2003;163:83-90.

38. Dracup K, Alonzo AA, Atkins JM, et al. The physician's role in minimizing prehospital delay in patients at high risk for acute myocardial infarction: recommendations from the National Heart Attack Alert Program. Ann Intern Med 1997;126:645-51.

39. Kaestle C, Campbell A, Finn J, Johnson S, Mikulecky L. Adult literacy and education in America: four studies based on the National Adult Literacy Survey. Washington, DC: National Center for Education Statistics; 2001. 